\title{
Awareness about effects of tobacco and areca-nut use in school children of Ahmedabad, India: A cross-sectional questionnaire-based survey
}

\author{
Priya Singh Rangey', Megha Sandeep Sheth², Azizfatema Khan ${ }^{3}$
}

\begin{abstract}
INTRODUCTION Tobacco use usually starts in the adolescent age group and continues in adulthood. This study's aim was to identify knowledge regarding the adverse effects of tobacco and areca-nut use among high school children of Ahmedabad, India.

METHODS An anonymous self-administered close-ended questionnaire was designed for the study. Principals of 9 schools, 3 municipal and 6 government-aided, were approached and written informed consent was obtained. A total of 3055 students studying in grades 7-12 were included. Data were analyzed using Microsoft Excel and SPSS 16.0. Chi-squared test was applied to investigate any differences between the responses of consumers and non-consumers, while Cramer's V was applied to analyze the strength of association between the awareness of ill-effects and tobacco product consumption.

RESULTS Of the 3055 children, $3 \%$ felt that tobacco use was definitely not harmful to health while $84 \%$ felt that it was. In all, $65 \%$ of respondents were aware that tobacco use caused cancer, $7 \%$ answered that it caused breathing problems, $5 \%$ said it caused heart problems, $0.3 \%$ answered that it caused paralysis, $4.3 \%$ felt it caused no health problems, whereas $18 \%$ thought that it caused multiple issues. With regards to the role of media, $78 \%$ had seen many anti-smoking warnings in the media, $15 \%$ had seen a few, $5 \%$ had seen none. There was a statistically significant difference between the tobacco users and and non-users with regards to exposure to media $(\mathrm{p}<0.001)$, discussions in class $(\mathrm{p}<0.001)$ and general awareness $(\mathrm{p}<0.001)$, but a weak association between awareness and tobacco consumption was identified $(\mathrm{p}<0.05)$.

CONCLUSIONS Awareness about the harmful effects of tobacco is high among school children of Ahmedabad, though use may still be prevalent.
\end{abstract}

\section{INTRODUCTION}

Tobacco use is a leading preventable cause of death worldwide; the situation is more morbid in developing nations like India ${ }^{1}$. In India, nearly 1 in 10 adolescents in the age group 13-15 years have ever smoked cigarettes and almost half of these report initiating tobacco use before 10 years of age ${ }^{2}$. Tobacco is easily accessible and legally available. It contributes significantly to premature death and long-term suffering. It is a risk factor for cardiovascular diseases, chronic obstructive pulmonary diseases, cancers and oral diseases ${ }^{3}$.

Tobacco is used in various forms, which include smoking and smokeless tobacco ${ }^{3}$. Bidi is the most popular form in rural areas while cigarettes are popular in urban areas. Chillum, hookah, cigars and pipes are other forms. Smokeless tobacco is consumed predominantly by chewing in the form of pan, pan-masala or gutkha, and mishri ${ }^{3}$. Areca nut is also commonly used together with tobacco. 
Most people are unaware of the side effects of areca nut. Areca nut is known to be mutagenic and has genotoxic effects on the tissues of the body, eventually leading to various neoplastic and paraneoplastic lesions ${ }^{4}$. Areca nut is the fourth most commonly used psychoactive substance in the world after nicotine, alcohol and caffeine ${ }^{5}$.

According to the Global Adult Tobacco SurveyIndia (GATS-India) 2009, more than one-third (34.6\%) of Indians use tobacco in some form: smoking, chewing, application to teeth and gums, or sniffing. Among the tobacco users, $20.6 \%$ consumed only smokeless tobacco, $8.7 \%$ smoking tobacco only, and $5.3 \%$ used both smoking as well as smokeless tobacco ${ }^{3}$. Tobacco use usually starts in the adolescent age group and continues in adulthood. According to WHO, adolescents are most vulnerable to risk-taking behavior that can lead to substance abuse. They are still going through critical periods of growth and development making them vulnerable to nicotine and its harmful effects ${ }^{6}$. Symptoms of serious addiction can appear within weeks or even days after smoking begins, which can lead to years of tobacco use and dependence ${ }^{7}$.

To reduce its prevalence, awareness should be increased, especially among school children because this is the most susceptible and easily modifiable age group. A study by Chadda and Sengupta ${ }^{6}$ concluded that there is a need to collect nationwide data on the use of different forms of tobacco by children and adolescents, and the factors leading to initiation of such harmful habits ${ }^{6}$. Schools play a powerful role in reducing tobacco and areca-nut use by children. The National Tobacco Control Programme (NTCP) includes training of school teachers and various school programs at the district level ${ }^{8}$. Despite such programs, a large number of adolescents is still addicted to tobacco in any form. Hence, this study was conducted, using a questionnaire, to determine the level of awareness about the risk associated with tobacco use among students of grades 7-12.

\section{METHODS}

This is a cross-sectional study conducted across 9 randomly selected schools ( 3 municipal and 6 government-aided) in Ahmedabad, India (Table 1).

The principals of the 9 schools were approached and written informed consent was obtained from all
Table 1. Distribution of the students

$\begin{array}{lccr} & \text { Viunicipal } & \text { Sermi Goverinment } & \text { Total } \\ \text { Boys } & 61(4 \%) & 1520(96 \%) & 1581 \\ \text { Girls } & 31(2.5 \%) & 1225(97.5 \%) & 1256 \\ \text { Users } & 24(6.5 \%) & 347(93.5 \%) & 371 \\ \text { Tobacco } & 0(0 \%) & 20(100 \%) & 20 \\ \text { Smoking } & 2(10 \%) & 18(90 \%) & 20 \\ \text { Areca-nut } & 22(7 \%) & 309(93 \%) & 331 \\ \text { Non-users } & 77(3 \%) & 2607(97 \%) & 2684\end{array}$

of them. Students from grades 7-12 were selected for the study and consent was also obtained from them. Students were informed about the purpose of the study and assurance was given about confidentiality. An anonymous self-administered close-ended questionnaire was designed for the study. They were asked to fill the questionnaire after they were given a brief explanation about it. The students were included in the study only after receipt of a written informed consent from the principal of the school and oral consent by the student. Any student who was unwilling to participate in the survey or did not understand the questionnaire (shown in the Supplementary File), even after explanation, was excluded.

The collected information was converted into a computer-based spreadsheet and analysed in Microsoft Excel 15.0. Data from 3055 students were analysed. Prevalence was calculated for each question answered. The chi-squared test was applied to analyze any differences between the responses of users and non-users.

\section{RESULTS}

Table 2 presents the association between tobacco use and participants characteristics, awareness and knowledge. The Cramer's V test (with measure $\varphi_{c}$ ) was applied to determine the strength of association between the users and non-users for the knowledge whether passive smoking was harmful or not. There was a weak association between the variables $\left(\varphi_{c}=0.08\right)$. Cramer's $\mathrm{V}$ demonstrates that the variables have a weak association for awareness that the habit is harmful and watching anti-smoking, chewing tobacco, sopari and alcohol drinking media messages on TV, etc $\left(\varphi_{c}=0.13\right.$ 
Table 2. Association between tobacco use and subject characteristics, awareness and knowledge

\begin{tabular}{|c|c|c|c|c|c|}
\hline & & $\begin{array}{l}\text { Users } \\
\text { n }(\%)\end{array}$ & $\begin{array}{l}\text { Non-users } \\
\text { in }(\%)\end{array}$ & Total & $p$ \\
\hline \multirow[t]{2}{*}{ Passive smoking - harmful } & No & $39(11 \%)$ & $153(6 \%)$ & 192 & $<0.001$ \\
\hline & Yes & $197(53 \%)$ & $1876(70 \%)$ & 2073 & \\
\hline \multirow[t]{2}{*}{ Habit - harmful } & No & $32(9 \%)$ & $64(3 \%)$ & 96 & $<0.001$ \\
\hline & Yes & $241(65 \%)$ & $2325(87 \%)$ & 2566 & \\
\hline \multirow[t]{3}{*}{ Anti-smoking media } & Many & $253(68 \%)$ & $2145(80 \%)$ & 2398 & $<0.001$ \\
\hline & Few & $69(19 \%)$ & $390(14 \%)$ & 459 & \\
\hline & None & $31(8 \%)$ & $111(4 \%)$ & 142 & \\
\hline \multirow[t]{6}{*}{ Problems caused by the habits } & Cancer & $226(61 \%)$ & $1748(65 \%)$ & 1974 & $<0.001$ \\
\hline & Breathing & $23(6 \%)$ & $185(7 \%)$ & 208 & \\
\hline & Heart & $10(3 \%)$ & $90(3 \%)$ & 100 & \\
\hline & Paralysis & $0(0 \%)$ & $10(0.3 \%)$ & 10 & \\
\hline & None & $61(17 \%)$ & $73(2.7 \%)$ & 134 & \\
\hline & Multiple & $51(13 \%)$ & $440(17 \%)$ & 552 & \\
\hline \multirow[t]{5}{*}{$\begin{array}{l}\text { Actors on TV/Movies/Video consuming } \\
\text { tobacco/ areca-nut/alcohol }\end{array}$} & $\begin{array}{l}\text { Never Watch TV/ } \\
\text { Movies }\end{array}$ & $18(5 \%)$ & $79(3 \%)$ & $97(3.2 \%)$ & $<0.001$ \\
\hline & Frequently & $213(57 \%)$ & $1549(58 \%)$ & $1762(57.8 \%)$ & \\
\hline & Sometimes & $102(27.5 \%)$ & $929(35 \%)$ & $1031(33.7 \%)$ & \\
\hline & Never & $17(4.5 \%)$ & $76(3 \%)$ & $93(3 \%)$ & \\
\hline & Missing & $21(6 \%)$ & $51(1 \%)$ & $72(2.3 \%)$ & \\
\hline \multirow[t]{4}{*}{ Ads/Promotions } & Many & $181(49 \%)$ & $1279(48 \%)$ & $1460(48 \%)$ & 0.0032 \\
\hline & Few & 107 (29\%) & $865(32 \%)$ & $972(32 \%)$ & \\
\hline & None & $63(17 \%)$ & $480(18 \%)$ & $543(17.7 \%)$ & \\
\hline & Missing & $20(5 \%)$ & $60(2 \%)$ & $80(2.3 \%)$ & \\
\hline \multirow[t]{4}{*}{ Discussion by the teacher } & Yes & $219(59 \%)$ & $1916(71 \%)$ & $2135(53 \%)$ & $<0.001$ \\
\hline & No & $78(21 \%)$ & $358(13 \%)$ & $436(23 \%)$ & \\
\hline & Not sure & $56(15 \%)$ & $347(13 \%)$ & $403(20 \%)$ & \\
\hline & Missing & $18(5 \%)$ & $63(3 \%)$ & $81(4 \%)$ & \\
\hline \multirow[t]{2}{*}{ Discussion in the class } & Yes & $178(48 \%)$ & $1451(54 \%)$ & $1629(53 \%)$ & $<0.001$ \\
\hline & No & $103(21 \%)$ & $606(23 \%)$ & 709 (23\%) & \\
\hline
\end{tabular}

and $\varphi_{c}=0.0848$, respectively). The test revealed a significant difference between the tobacco users and non-users but a weak association for belief that the habit caused cancer, breathing problems, heart problems, paralysis or it did not cause any problems or caused multiple problems $\left(\mathrm{p}<0.001, \varphi_{\mathrm{c}}=0.198\right)$. Chi-square tests revealed a significant difference between tobacco users and non-users and a weak association for whether they had seen any actors smoking or chewing tobacco or sopari or drinking alcohol on screen $\left(\mathrm{p}<0.001, \phi_{\mathrm{c}}=0.1\right)$ or promotional advertisements $\left(p=0.032, \varphi_{c}=0.067\right)$. Chi-squared tests also showed statistically significant differences for whether their teacher had talked about the dangers of such habits $(p<0.001)$ and for whether there had been any discussion about the ill-effects of smoking in class $(\mathrm{p}<0.001)$. Cramer's V showed a weak association for the same $\left(\varphi_{c}=0.098\right.$ and $\varphi_{c}=0.301$, respectively).

\section{DISCUSSION}

This study determined the awareness about the use of tobacco and areca nut among school children in India. The majority of children were aware of the health effects, but $3-6 \%$ of the children may not be aware of the ill-effects of such use. The results of 
the present study are in accordance with the results found by Taran et al. ${ }^{9}$ in 2016 and Tiwari et al. ${ }^{10}$ in 2014. The authors found that $50-90 \%$ of the children were aware of the ill-effects of tobacco use. Also, 23\% did not recall any discussion in the class or any talks by the teacher regarding the ill-effects of tobacco or areca-nut usage. There is good awareness about the ill-effects of the usage, but measures need to be taken to combat tobacco use in India. The benefits of early educational programs have been well reported for school children ${ }^{11}$. Out of the tobacco users in our sample, the majority knew about the ill-effects caused by areca-nut and tobacco use but still chose to use it, whereas a small percentage was unaware of the risks. These results are contradictory to the findings of Khandelwal et al. ${ }^{12}$ who found that $70 \%$ of the users were uninformed of the harmful effects of areca-nut use. Such programs should not only focus on the harms caused by cigarette smoking but also on those caused by other forms of tobacco use, like smoking hooka and bidis, and by the smokeless forms like gutka and areca nut.

Almost half of the students had seen actors consuming tobacco, areca nut or alcohol on TV, in movies or videos, as well as advertisements or promotions for tobacco use. Such actions lead the youth to become more attracted to such products. Tobacco or areca-nut advertising and promotion effectively target young people with images of smokers as trendy, sporty and successful. Characters in the movies or television serials often demonstrate cigarette smoking or alcohol consumption as a routine of daily life. These scenes often stimulate the impressionable mind of the adolescent to adopt similar behaviour ${ }^{6}$.

The results showed a statistically significant difference between tobacco users and non-users, but there was only a weak association. Increasing awareness may lead to reduced consumption in the adolescents as they may have lower awareness levels. Hence, we need to propose new ideas and techniques for spreading awareness and reducing the consumption of tobacco or areca nut. But since the association is only weak, it cannot be said that an increased awareness may lead to reduced consumption. Special attention needs to be given to promoting cessation among current users, as helping them would, in turn, be beneficial for the other students who are tobacco non-users and may be influenced by them.

The current study focused on a small sample. Future studies with larger samples need to be performed. Furthermore, the present study was limited to urban areas of Ahmedabad, hence studies in rural areas and other parts of the country are warranted.

\section{CONCLUSIONS}

There is awareness about the ill-effects of tobacco and areca-nut use among the school children of Ahmedabad, but there is still a need to develop programs to combat usage of these products as some of the children still tend to use them despite being aware of the associated risks. There should be better provisions developed for those who are consumers to aid cessation efforts. Schools need to focus more on such areas, and there should be better legislation at the regional level for controlling the promotion and advertising of tobacco.

\section{REFERENCES}

1. Narain R, Sardana S, Gupta S, et al. Age at initiation \& prevalence of tobacco use among school children in Noida, India: A cross-sectional questionnaire based survey. Indian J Med Res. 2011;133(3):300-7.

2. Sinha DN, Reddy KS, Rahman K, Warren CW, Jones NR, Asma S. Linking Global Youth Tobacco Survey (GYTS) data to the WHO framework convention on tobacco control: the case for India. Indian J Public Health. 2006;Apr-Jun 50(2):76-89.

3. Gupta Bhawan. Burden of Smoked and Smokeless Tobacco Consumption in India - Results from the Global adult Tobacco Survey India (GATS-India)2009-2010. Asian Pacific Journal of Cancer Prevention. 2013;14(5):3323-9.

4. Trivedy CR, Craig G, Warnakulasuriya S. The oral health consequences of chewing areca nut. Addiction Biology. 2002;7(1):115-25. doi:10.1080/13556210120091482

5. Auluck A, Hislop G, Poh C, Zhang L, Rosin MP. Areca nut and betel quid chewing among South Asian immigrants to Western countries and its implications for oral cancer screening. Rural Remote Health. 2009;9:1118.

6. Chadda RK, Sengupta SN. Tobacco use by Indian adolescents. Tob Induc Dis. 2003;1(1):8. doi:10.1186/1617-9625-1-8

7. DiFranza JR, Rigotti NA, McNeill AD, et al. Initial Symptoms of Nicotine Dependence in Adolescents. Tob Control. 2000;9(3):313-9. doi:10.1136/tc.9.3.31

8. Kaur J, Jain DC. Tobacco Control Policies in India: Implementation and Challenges. Indian J Public Health. 
2011;55(3):220-7. doi:10.4103/0019-557x.89941

9. Taran SJ, Taran R, Saroshe S, Bhandari V. A cross sectional study to assess the prevalence and awareness of tobacco consumption among school students in a cosmopolitan city of India. Int J Contemp Pediatr. 2016 Feb;3(1):86-90. doi:10.18203/2349-3291.ijcp20160076

10. Tiwari RV, Megalamanegowdru J, Gupta A,et al. Knowledge, Attitude and Practice of Tobacco Use and Oral Health of Children in Chhattisgarh, India. Asian Pacific Journal of Cancer Prevention. 2014 Jan;15(23):1012935. doi:10.7314/apjcp.2014.15.23.10129

11. Swadi H, Zeitlin H: Drug education to school children: does it really work? British Journal of Addiction. 1987,82(7):741-746. doi:10.1111/j.1360-0443.1987.tb01540.x

12. Khandelwal A, Khandelwal V, Saha MK, Khandelwal S, Prasad S, Saha SG. Prevalence of areca nut chewing in the middle school going children of Indore, India. Contemporary Clinical Dentistry. Apr-Jun 2012;3(2):155-157. doi:10.4103/0976-237x.96817

ACKNOWLEDGEMENTS The authors would like to acknowledge all the students who participated in the study and the principals of all the schools.

CONFLICTS OF INTEREST Authors have completed and submitted the ICMJE Form for Disclosure of Potential Conflicts of Interest and none was reported.

FUNDING

There was no source of funding for this research.

PROVENANCE AND PEER REVIEW

Not commissioned; externally peer reviewed. 